\title{
A randomised controlled trial of cognitive behaviour therapy versus non-directive reflective listening for young people at ultra high risk of developing psychosis
} DOI:

10.1016/j.schres.2016.08.008

10.1016/j.schres.2016.08.008

\section{Document Version}

Accepted author manuscript

Link to publication record in Manchester Research Explorer

Citation for published version (APA):

Stain, H. J., Bucci, S., Baker, A. L., Carr, V., Emsley, R., Halpin, S., Lewin, T. J., Schall, U., Clarke, V., Crittenden, K., \& Startup, M. (2016). A randomised controlled trial of cognitive behaviour therapy versus non-directive reflective listening for young people at ultra high risk of developing psychosis: The detection and evaluation of psychological therapy (DEPTh) trial. Schizophrenia Research, 176(2-3), 212-219.

https://doi.org/10.1016/j.schres.2016.08.008, https://doi.org/10.1016/j.schres.2016.08.008

\section{Published in:}

Schizophrenia Research

\section{Citing this paper}

Please note that where the full-text provided on Manchester Research Explorer is the Author Accepted Manuscript or Proof version this may differ from the final Published version. If citing, it is advised that you check and use the publisher's definitive version.

\section{General rights}

Copyright and moral rights for the publications made accessible in the Research Explorer are retained by the authors and/or other copyright owners and it is a condition of accessing publications that users recognise and abide by the legal requirements associated with these rights.

\section{Takedown policy}

If you believe that this document breaches copyright please refer to the University of Manchester's Takedown Procedures [http://man.ac.uk/04Y6Bo] or contact uml.scholarlycommunications@manchester.ac.uk providing relevant details, so we can investigate your claim.

\section{OPEN ACCESS}




\section{A randomised controlled trial of cognitive behaviour therapy versus non-directive reflective listening for young people at ultra high risk of developing psychosis: The detection and evaluation of psychological therapy (DEPTh) trial}

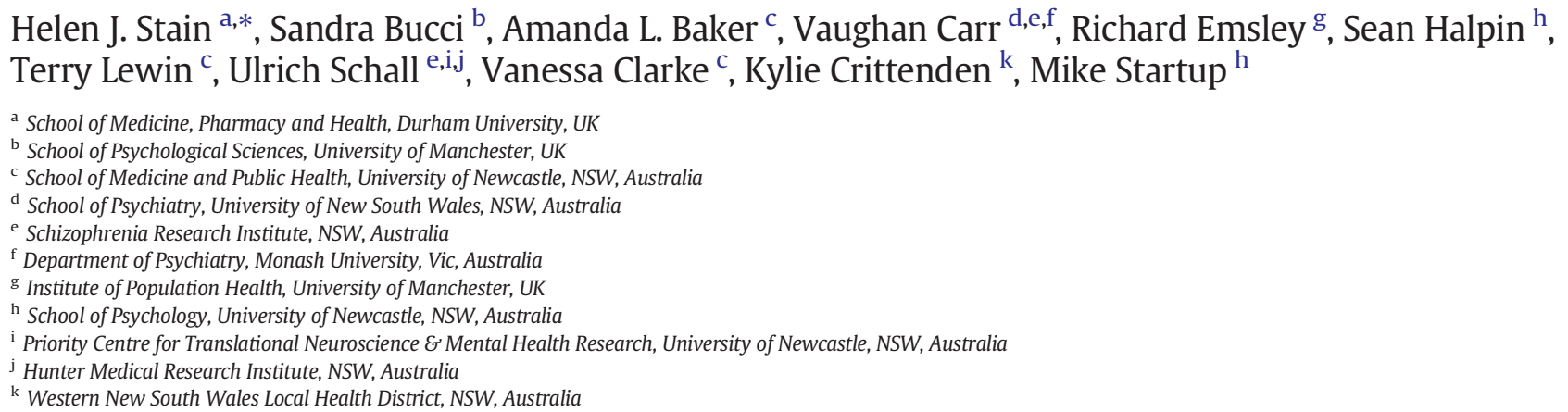

${ }^{\mathrm{k}}$ Western New South Wales Local Health District, NSW, Australia

\section{A R T I C L E I N F O}

\section{Article history:}

Received 10 March 2016

Received in revised form 7 August 2016

Accepted 8 August 2016

Available online $\mathrm{xxxx}$

\section{Keywords:}

Ultra high risk

At risk mental state

Intervention

Psychosis

Youth

\begin{abstract}
A B S T R A C T
Background: Intervention trials for young people at ultra high risk (UHR) for psychosis have shown cognitive behaviour therapy (CBT) to have promising effects on treating psychotic symptoms but have not focused on functional outcomes. We hypothesized that compared to an active control, CBT would: (i) reduce the likelihood of, and/or delay, transition to psychosis; (ii) reduce symptom severity while improving social functioning and quality of life, whether or not transition occurred.

Method: This was a single-blind randomised controlled trial for young people at UHR for psychosis comparing CBT to an active control condition, Non Directive Reflective Listening (NDRL), both in addition to standard care, with a 6 month treatment phase and 12 months of follow-up. Statistical analysis is based on intention-totreat and used random effect models to estimate treatment effects common to all time-points.

Results: Fifty-seven young people (mean age $=16.5$ years) were randomised to CBT ( $n=30)$ or NDRL $(n=27)$. Rate of transition to psychosis was 5\%; the 3 transitions occurred in the CBT condition (baseline, 2 months, 5 months respectively). The NDRL condition resulted in a significantly greater reduction in distress associated with psychotic symptoms compared to CBT (treatment effect $=36.71$, standard error $=16.84, p=0.029$ ). There were no significant treatment effects on frequency and intensity of psychotic symptoms, global, social or role functioning.

Conclusion: Our sample was higher functioning, younger and experiencing lower levels of psychotic like experiences than other trials. The significantly better treatment effect of NDRL on distress associated with psychotic symptoms supports the recommendations for a stepped-care model of service delivery. This treatment approach would accommodate the younger UHR population and facilitate timely intervention.

Trial registration: ANZCTR 12606000101583
\end{abstract}

(c) 2016 Elsevier B.V. All rights reserved.
* Corresponding author at: School of Medicine, Pharmacy and Health, Durham University, Queens Campus, University Boulevard, Stockton on Tees TS17 6BH, UK.

E-mail address: helen.stain@durham.ac.uk (H.J. Stain).

\section{Introduction}

Nearly one fifth of the global population is comprised of young people aged 14-24 years (Fisher and de Mello, 2011). Mental health and behavioural difficulties are the leading causes of health problems in this group, accounting for one third of all years of lost productivity due to 
disability (WHO, 2008) Approximately 20\% of young people experience a mental health problem each year (Patel et al., 2007; UNICEF, 2012) and young people are at greater risk of developing mental ill-health as they transition from childhood to adulthood (Kessler et al., 2005). Indeed, epidemiological research suggests that the majority of individuals first experience mental health symptoms prior to age 24 (Kessler et al., 2005). The emergence of serious mental health problems in adolescence disrupts development in various ways, including the attainment of educational goals and relationship skills, thus reducing social inclusion in adulthood resulting in high economic and social burden. Psychosis has been described as a serious mental illness due to the associated disability across the lifespan including lost opportunity for education, employment and relationships (Morgan et al., 2012).

The concept for developing and defining the ultra high risk (UHR) for psychosis group came from retrospective studies of prodromal symptoms in individuals presenting with their first psychotic episode, where studies highlighted that the majority of individuals experienced psychiatric symptoms prior to the onset of the psychotic disorder (Chapman, 1966; Yung and McGorry, 1996). A set of criteria was produced to identify a group at imminent risk of developing a psychotic disorder on the basis of presenting symptoms and associated risk factors. The UHR for psychosis state is characterised by the presence of low intensity/frequency psychotic symptoms, brief limited psychotic episodes, and/or familial risk and/or schizotypal personality disorder in the presence of psychosocial functional decline. The rate of development of psychosis in this group is high both in the short-term (FusarPoli et al., 2012) and the long-term (Nelson et al., 2013). Young people meeting these criteria who present to clinical services are struggling in multiple areas of their lives. The UHR criteria provide an important opportunity for early intervention in preventing or delaying the onset of psychosis and reducing the social and economic burden associated with long-term mental health problems.

Interventions trialed for young people at UHR for psychosis include randomised controlled trials (RCT) comparing pharmacological (low dose antipsychotics; McGorry et al., 2002), nutritional (Omega 3 fatty acids; Amminger et al., 2010), and/or psychological therapies (primarily cognitive behaviour therapy; CBT; Morrison et al., 2012). A metaanalysis of such trials identified only 11 RCTs, with seven of these trials involving CBT (Stafford et al., 2013) and four involving integrated therapy or omega 3 fatty acids intervention. For this meta-analysis, results from four trials comparing CBT to supportive counseling showed moderate quality evidence for fewer transitions to psychosis in the CBT group at 12 months. The results for five trials examining CBT within a meta-analysis of interventions for UHR for psychosis found the number needed to treat (NNT) for one person to avoid transition to psychosis was 11 (van der Gaag et al., 2013). A more recent meta-analysis focused on CBT identified six published trials (Hutton and Taylor, 2014). Results from this meta-analysis showed the relative risk (RR) for developing psychosis for those receiving CBT was reduced by at least $50 \%$ at six, 12 and 18-24 months. The NNT for one person to avoid transition to psychosis (at 12-24 months) was eight to 11 . While CBT was associated with reduced subthreshold symptoms at 12 months, there was no effect on functioning, symptom related distress or quality of life.

These meta-analyses highlighted a critical limitation with the RCTs to date, namely, the focus on the primary outcome as a dichotomous one of transition to psychosis, rather than the dimensional domains of functioning, mood and quality of life. Few trials reported on these latter outcomes and therefore restrict the findings available from meta-analyses. Our RCT of CBT was designed to measure both transition and functional outcomes. We controlled for non-specific aspects of treatment by using an active control treatment, Non Directive Reflective Listening (NDRL). We hypothesized that, compared to the active control, CBT would: (i) reduce the likelihood of, and/or delay, transition to psychosis; and (ii) reduce symptom severity while improving social functioning and quality of life, whether or not transition occurred.

\section{Method}

\subsection{Trial design}

This study was a single-blind RCT of CBT compared to NDRL in addition to standard care, conducted at two sites with a six month treatment phase and 12 months of follow-up after randomisation. The study was known as the Detection and Evaluation of Psychological Therapy (DEPTh) trial. Treatment began within two weeks of completion of the baseline assessment and was available for up to 26 sessions over a sixmonth period. Follow up assessments were conducted at monthly intervals for the first six months and bi-monthly for the next 6 months. Recruitment continued for two years as per funding conditions. Ethical approval was obtained from the relevant human research ethics committees or participating institutions. The trial was registered with the Australian and New Zealand Clinical Trial Register $(12,606,000,101,583)$. Clinical raters were blind to treatment groups.

\subsection{Setting}

This study was conducted at the urban location of the Psychological Assistance Service (PAS; Conrad et al., 2014) in Newcastle, and the rural location of the Centre for Rural and Remote Mental Health (CRRMH), Orange, New South Wales, Australia. PAS is a specialist early intervention service modeled on the Personal Assessment and Crisis Evaluation (PACE) clinic (Carr et al., 2000). Its primary function is to identify and treat young people experiencing or at increased risk of psychosis. CRRMH is an academic unit of the University of Newcastle funded primarily by the New South Wales Health Department and housed within the regional mental health services. CCRMH provided research knowledge to clinical services to enhance identification and intervention for UHR young people. Both settings are designed to provide a nonstigmatising environment.

\subsection{Participants}

Participants eligible for inclusion were: 1 . aged 14 to 30 years (based on referral criteria for the services), 2. resided within the boundaries of one of the relevant Health Services, and 3. met criteria for UHR status defined by the CAARMS (Yung et al., 2005). Participants were excluded if they met any of the following criteria: 1 . past or current DSM-IV psychotic disorder, 2. previously prescribed antipsychotic medication, 3. organic mental disorder or intellectual disability, 4. at serious suicidal/ homicidal risk (they were eligible for inclusion once this risk had resolved), or 5. inadequate command of the English language. The transition criterion for the trial was the presence of psychotic symptoms for more than one week as defined by the CAARMS (Yung et al., 2005).

\subsection{Measures}

The UHR status, and the presence and severity of psychotic symptoms were measured by the CAARMS (Yung et al., 2005) and diagnosis of psychiatric disorder by the SCID(First et al., 1996) or K-SADS (Kaufman et al., 1997) depending on age of the participant (less than or greater than/equal to 18 years). Other clinical symptoms were measured by the Brief Symptom Inventory (Derogatis, 1995). The Social and Occupational Functioning Assessment Scale (SOFAS; Goldman et al., 1992), Global Assessment of Functioning (GAF; Association, 1994), and the Quality of Life Scale (Heinrichs et al., 1984) were used to assess levels of functioning. Frequency of substance use was measured by the Drug Use Scale of the Opiate Treatment Index (OTI; Darke et al., 1992), Alcohol Use Disorders Identification Test (Babor et al., 2001), Cannabis Use Disorders Identification Test(Adamson et al., 2010) and the five-item Severity of Dependence Scale (Cannabis)(Gossop et al., 1995). The following measures were not included in the current analysis: the Rosenberg Self Esteem Scale 
(Rosenberg, 1965) and the Meta-cognitions Questionnaire (CartwrightHatton and Wells, 1997). The entire battery of measures was not used at each assessment in order to limit the burden on participants. Assessments occurred at baseline, 1, 2, 3, 4, 5, 6, 8, 10 and 12 months. All of the measures used are valid and reliable and widely used in mental health research.

\subsection{Procedure}

Recruitment to the urban site was from people seeking help at PAS while recruitment to the rural site was on referral to child and youth related services. Referral sources were primary healthcare services, community adolescent teams, community mental health services, self-referrals, counseling services and other youth-related services. Recruitment was facilitated by presentations by research assistants at clinical team meetings, advertisements in local clinical settings, and liaison with youth-related services. All potentially eligible participants met criteria on the CAARMS following interview with an assessor. Participants were reimbursed \$AUD20 for time and travel at each assessment occasion. After receiving a complete description of the study, participants provided written informed consent. Parental consent was obtained from a parent or guardian of participants under 16 years of age. Assessors were experienced research clinicians who received training and regular supervision by senior members of the research team. Raters demonstrated adequate reliability at routine reliability checks with MS.

\subsection{Sample size}

Based on an effect size of XX, as found in the EDIE trial (Morrison et al., 2004) for those making a transition to psychosis within six months, the sample required to have $80 \%$ power with $5 \%$ significance for a two-tailed test of differences in proportions was 39 in each treatment arm.

\subsection{Randomisation}

Randomisation was stratified by site to control for location-specific (urban vs rural) factors, and by current prescription of antidepressant medication by the participant's physician, using a system of central and external randomisation. The random allocation list was generated by using computer-generated block randomisation, such that within every six allocations for a particular stratification cell (i.e. centre by medication status combination) there were an equivalent number of CBT and NDRL allocations. The allocation list was kept in a secure location by an independent clerical worker, not accessible by the research team. Following randomisation, the clerical worker informed the therapist by email of treatment allocation. Research assistants who completed assessments remained blind to randomisation. Extensive steps were taken to maintain blindness of raters. Therapist and raters did not discuss details of individual participants. Office work and data storage were kept separate and secure. Prior to each assessment, the assessor clearly stated that the participant should not talk about therapy condition or therapist. Blinding was broken in one case, after the initial assessment, but prior to commencing therapy. In this case, the participant was re-randomised.

\subsection{Interventions}

The same therapists delivered both CBT and NDRL. This can help to keep follow up assessment blind to treatment assignment, as mention of the therapist's name alone will not unblind the assessor. It also has the advantage of controlling for non-specific aspects of treatment (e.g. therapist age, sex, personality, therapist experience), but entails the danger that the therapist will carry over strategies from one treatment to the other. To guard against this, each intervention followed a prescribed treatment manual and therapist adherence checks were conducted during clinical supervision sessions. Therapists completed a three day intensive CBT workshop led by French based on the French and Morrison (2004) protocol. Therapists also completed a three day intensive NDRL workshop, led by $\mathrm{AB}$, who had extensive experience using this model among people with co-existing depression and alcohol misuse. NDRL was based on a treatment manual developed by Sellman and colleagues (Sellman et al., 2001). Participants were asked at the outset of treatment to commit to attend at least eight therapy sessions. Session frequency was collaboratively agreed and each session lasted up to an hour in duration in a mutually agreed community based site.

\subsubsection{Cognitive behaviour therapy}

The CBT intervention followed the manual developed by French and Morrison (2004) and is based on a formulation-driven cognitive model that prioritises a collaboratively agreed problem list. It is problemoriented, time-limited and educational, using collaborative empiricism with guided discovery, behavioural experiments and homework tasks. The model draws on strategies for change, including normalising, generating and evaluating alternative beliefs, safety behaviours, metacognitions, core beliefs, social isolation and relapse prevention. Strategies used were selected in accordance with the formulation and key problems identified on the participant's problem list. The model was enriched with Motivational Interviewing-CBT (Mi-CBT) skills for those who presented with hazardous substance misuse and was based on a manual developed by Bucci and Baker (unpublished).

\subsubsection{Non-directive reflective listening}

This treatment followed that employed as a control condition by Sellman et al. (2001), as described in their manual (Sellman et al., 2007). The purpose of the active psychological treatment was to match CBT for the many non-specific effects of therapist contact. NDRL is a form of person-centred counseling in which, within a therapeutic setting, the therapist offers empathic reflections while adopting a stance of genuineness and unconditional positive regard. Participants were invited to discuss any topics of their choice, not necessarily issues related to UHR mental states, and participants determined the direction of content throughout the sessions. No active CBT concepts or techniques were employed.

\subsubsection{Standard care}

All participants were offered psychiatric medication and casework according to need. However, no anti-psychotic medication was prescribed unless/until participants met criteria for the onset of a psychotic episode. Casework was limited to assistance with accommodation, education and employment, and brief family education and support if indicated (not structured family intervention). Prescription and management of medication was the responsibility of medical staff who were in contact with, but not involved in, the research study and were blind to treatment allocation.

All therapy sessions were delivered by qualified psychologists (PAS, $n=5$; CRRMH, $n=2$ ). All therapists were experienced in CBT and at least one other model of intervention, and had extensive experience working with UHR clients, ranging from three to 30 years experience. At each site, therapists received expert and peer supervision at least fortnightly by well-established video-conference facilities to ensure adherence to each treatment model and to the protocol. Supervisors regularly reviewed therapist audio-recordings during group supervision sessions.

\subsection{Treatment fidelity}

All treatment sessions were audiotaped (with participants' consent). Therapist adherence to the CBT and NDRL interventions was measured on the Cognitive Therapy for At Risk Populations Adherence Scale (CTARPAS; Bell et al., 2008). The CTARPAS is a nine-item scale that was developed specifically to rate therapist adherence to the French 
and Morrison (2004) manual of cognitive therapy for people at high risk of developing psychosis. Therapists were considered adherent to NDRL if they received no ratings on the CTARPAS.

\subsection{Outcomes}

\subsubsection{Primary outcome}

The primary outcome was transition to psychosis as defined by the CAARMS criteria and verified by the SCID or the K-SADS, depending on participant age. The primary end point was at 12 months. Assessments were performed at baseline and at 1, 2, 3, 4, 5, 6, 8, 10 and 12 months, or at the moment a therapist noted that a transition had appeared to have taken place (in the therapy session or by notice from the referrer).

\subsubsection{Secondary outcomes}

The secondary outcomes were severity of psychotic symptoms and distress associated with psychotic symptoms, as well as depression, anxiety, social functioning and quality of life.

\subsection{Statistical analysis}

Analyses were undertaken in STATA (version 13). Primary analysis was by intention-to-treat principle and reported in line with the CONSORT statement. The primary outcome of transition was compared using logistic regression to estimate the odds ratio for transition, and
Cox proportional hazards model for time-to-transition. Covariates were site, antidepressant status, gender and age. Secondary outcomes were analysed with STATA's xtreg command to fit random effect regression models (essentially a series of repeated measures ANCOVAs) with maximum likelihood estimation. Covariates were time (months), site, antidepressant status, gender, age and the baseline value of the relevant outcome measure. The models allowed for analysis of all available data, under the assumption that data were missing at random conditional on the covariates. All models were bootstrapped with 500 replications. We report estimated treatment effects, with their bootstrapped standard errors, significance levels, and 95\% CIs. All treatment effects reported here are estimates of the effects common to all follow-up times.

\section{Results}

\subsection{Full sample}

A total of 564 people were referred to the trial between May 2006 to August 2008 (see Fig. 1). There were 232 people excluded after referral primarily because they either did not meet the inclusion criteria or they declined assessment. A screening interview using the CAARMS was conducted with 332 people. Of these, 171 were further excluded, because they did not meet the inclusion criteria (69\%), they declined assessment (22\%), or for reasons not known (9\%). The baseline assessment was completed by 161 people (rural: $n=44$; urban: $n=117$ ) and 60 people met the inclusion criteria, 57 consented to the trial and were

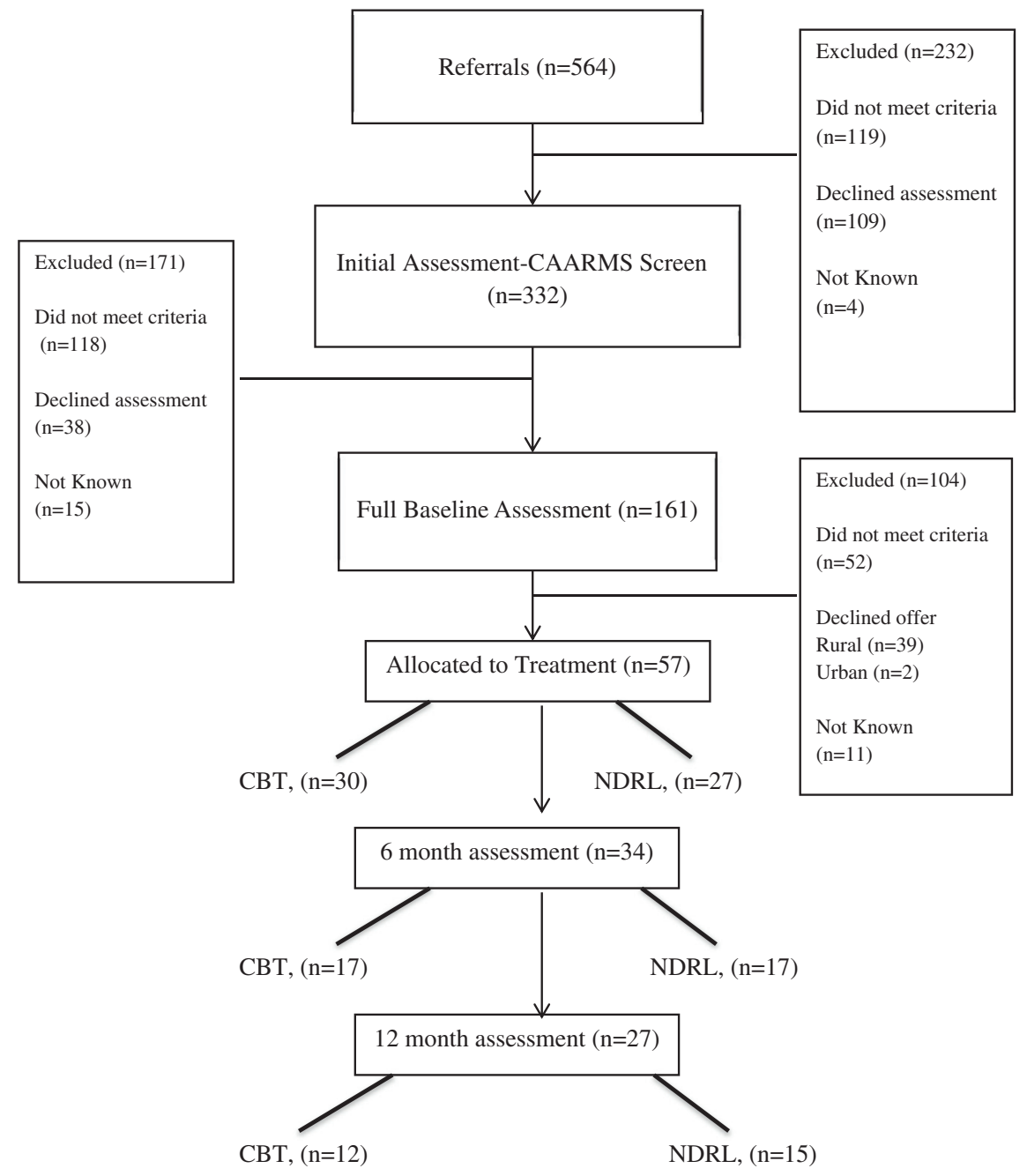

Fig. 1. Consort chart. 
randomised to either CBT or NDRL (rural: $n=32$; urban: $n=25$ ). Of the 161 who completed the baseline assessment, 52 people did not meet inclusion criteria, 38 people declined the offer to participate, and the reason for non-participation was unknown in 11 cases. Participants who met study transition criteria were assessed by a Consultant Psychiatrist (US) using DSM-IV diagnostic criteria (Association, 1994) and entered into routine health service treatment pathways accordingly.

Of the 564 young people referred to the trial, 332 were screened, 161 completed baseline assessment and 57 were randomised for treatment. This was a young UHR sample (mean age 16.46 years) with slightly more females than males. The majority of participants were living with their families and attending education. Around one third did not meet criteria for any diagnosis while a third met DSM-IV diagnostic criteria (Association, 1994) for mood disorder (predominantly major depressive disorder) and 9 (16\%) for anxiety disorder (see Table 1 ). CAARMS groupings were: 46 (81\%) attenuated, 4 (7\%) BLIPS and 19 (33\%) family history or schizotypal personality. There was a high attrition rate of $53 \%$, with 12 month outcomes collected on only 27 participants.

\subsection{Baseline data}

The baseline values of the outcome measures are shown in Table 2 . The CBT group had greater distress levels associated with psychotic symptoms at baseline compared to NDRL. However, both groups scored similarly on the Global Severity of Symptoms Index.

\subsection{Treatment sessions}

The mean number of sessions completed was 9.2 for CBT ( $3 \%$ had no sessions, $17 \%$ had $1-5,47 \%$ had $6-11,30 \%$ had $12-26$ ), and 10.1 for NDRL (4\% had no sessions, $26 \%$ had $1-5,37 \%$ had $6-11,33 \%$ had $12-26$ ).

Table 1

Demographic and clinical characteristics of sample at baseline by treatment group.

\begin{tabular}{|c|c|c|}
\hline Baseline characteristics & CBT group $(\mathrm{N}=30)$ & NDRL group $(\mathrm{N}=27)$ \\
\hline Age in years (mean, $S D$ ) & $16.20(2.73)$ & $16.47(3.16)$ \\
\hline \multicolumn{3}{|l|}{ Site $(N(\%))$} \\
\hline Urban & $13(52)$ & $12(48)$ \\
\hline Rural & $17(53)$ & $15(47)$ \\
\hline \multicolumn{3}{|l|}{ Antidepressant use (N (\%)) } \\
\hline Not using & $23(77)$ & $20(74)$ \\
\hline Using & $7(23)$ & $7(26)$ \\
\hline \multicolumn{3}{|l|}{ Education in years $(\mathrm{N}(\%))$} \\
\hline Primary/secondary non-complete & $22(73)$ & $17(63)$ \\
\hline Secondary and above & $8(27)$ & $10(37)$ \\
\hline Gender (N (\%) female) & $20(67)$ & $14(52)$ \\
\hline \multicolumn{3}{|l|}{ Marital status (N (\%)) } \\
\hline Never married & $28(93)$ & $25(93)$ \\
\hline Partnered & $1(3)$ & $2(7)$ \\
\hline Divorced/separated/widowed & $1(3)$ & $0(0)$ \\
\hline \multicolumn{3}{|l|}{ Role Function (N (\%)) } \\
\hline Paid work & $2(7)$ & $5(19)$ \\
\hline Studying & $19(63)$ & $17(63)$ \\
\hline Neither & $9(30)$ & $5(19)$ \\
\hline \multicolumn{3}{|l|}{ Living situation (N (\%)) } \\
\hline Family home & $24(80)$ & $20(74)$ \\
\hline Shared housing & $5(17)$ & $4(15)$ \\
\hline Crisis shelter & $1(3)$ & $3(11)$ \\
\hline Positive symptoms (CAARMS) & 10.17 (4.53), $\mathrm{N}=28$ & 9.50 (3.49), $N=24$ \\
\hline Negative symptoms (CAARMS) & $5.96(4.01), \mathrm{N}=28$ & $6.24(4.29), \mathrm{N}=25$ \\
\hline \multicolumn{3}{|l|}{ Primary diagnosis (\%) } \\
\hline Mood disorder & $9(30)$ & $10(37)$ \\
\hline Anxiety disorder & $5(17)$ & $4(15)$ \\
\hline Substance use disorder & $2(7)$ & $0(0)$ \\
\hline $\begin{array}{l}\text { Neurodevelopmental/Behavioural } \\
\text { Disorder }\end{array}$ & $4(13)$ & $2(7)$ \\
\hline Brief psychiatric disorder & $0(0)$ & $1(4)$ \\
\hline None & $10(33)$ & $10(37)$ \\
\hline
\end{tabular}

\subsection{Primary outcome}

The transition to psychosis rate was $5 \%$, with all three transitions occurring in the CBT condition at baseline, two months and five months. Since there were no transitions in the NDRL group, we were unable to perform any further analysis on the primary outcome.

\subsection{Secondary outcomes}

The results on distress associated with subclinical psychotic symptoms showed a significant treatment effect in favour of the NDRL condition (CAARMS distress: treatment effect $=36.71$ ( $\mathrm{SE}=16.84, \mathrm{p}=$ 0.029 ). There were no significant treatment effects on frequency or intensity of psychotic like experiences; anxiety, depression or overall symptom severity; or on global, social or role functioning. Estimates of the treatment effects and their confidence intervals are given in Table 3.

\subsection{At risk status at 12 month follow up}

At 12 month follow up, 2 (16\%) of the CBT group and 1 (7\%) of the NDRL group met attenuated criteria. None of the participants assessed at the 12 month follow-up met the BLIPS criteria.

\subsection{Treatment fidelity}

To address the degree of agreement between fidelity raters, a random selection of recorded therapy sessions ( $\mathrm{n}=15$ CBT sessions; $\mathrm{n}=9$ NDRL sessions) was rated by MS and a clinical psychologist who was independent of the trial and had 30 years experience using CBT for serious mental health problems. All kappa estimates of interrater reliability on the CTARPAS items in the CBT intervention were above 0.75 , which is indicative of excellent inter-rater reliability. A percentage agreement calculation found that both raters agreed on $99 \%$ of ratings in the NDRL intervention. Discrimination between the CBT and NDRL interventions was also assessed, with $100 \%$ agreement between the two raters in relation to assessing whether the intervention session rated was an example of CBT or NDRL. Fifty-five sessions (32 CBT; 23 NDRL) from a random sample of a third of participants were rated for fidelity. Therapists, when delivering the NDRL intervention, did not engage in any proscribed activities as measured by the CTARPAS. Therapists delivering both the CBT and NDRL interventions were rated as adherent and competent.

\section{Discussion}

The DEPTh trial is one of very few RCTs of CBT for young people at ultra high risk for psychosis. The trial targeted a younger sample than most trials and employed an active control condition. We hypothesized that, compared to an active control treatment, CBT would reduce the likelihood of, and delay transition to, psychosis, and would reduce symptom severity and improve social functioning and quality of life, whether or not transition occurred. While meta-analyses have shown an effect for CBT in reducing transition to psychosis (Hutton and Taylor, 2014; Stafford et al., 2013; van der Gaag et al., 2013), these have been based on a small number of trials and there has been a lack of focus on functional outcomes. Results from our trial showed that the active control condition, NDRL, resulted in a significantly greater reduction in distress associated with psychotic symptoms compared to CBT. Both CBT and NDRL showed reductions in the frequency and intensity of psychotic symptoms over time. There were no significant treatment effects on global, social or role functioning.

Our transition rate of $5 \%$ is substantially lower than other trials (16.3\%; van der Gaag et al., 2013); (10-21\%; McGorry et al., 2013); (8\%; Morrison et al., 2012); (22\%; Morrison et al., 2012); (6-20\%; Bechdolf et al., 2012)) with transitions in our CBT group occurring at baseline, two and five months. This low rate is likely reflective of our 
Table 2

Outcome measures at baseline, 6 and 12 months by randomised treatment group.

\begin{tabular}{|c|c|c|c|c|c|c|}
\hline \multirow[t]{2}{*}{ Measure } & \multicolumn{2}{|l|}{ Baseline } & \multicolumn{2}{|l|}{6 months } & \multicolumn{2}{|l|}{12 months } \\
\hline & CBT group & NDRL group & CBT group & NDRL group & CBT group & NDRL group \\
\hline Transitions & 1 & 0 & 3 & 0 & 3 & 0 \\
\hline CAARMS intensity & 10.03 (4.52); 29 & $9.56(3.71) ; 27$ & 3.71 (5.19); 17 & $1.71(2.64) ; 17$ & 2.33 (3.39); 12 & 2.07 (2.15); 15 \\
\hline CAARMS frequency & $9.72(4.25) ; 29$ & 10.85 (4.59); 27 & $4.94(5.91) ; 17$ & $1.82(3.70) ; 17$ & 2.50 (4.30); 12 & 2.40 (2.95); 15 \\
\hline CAARMS distress & 177.21 (97.94); 24 & $126.92(77.34) ; 24$ & 83.56 (109.29); 16 & $12.06(26.75) ; 17$ & $55.00(79.60) ; 12$ & $41.80(55.38) ; 15$ \\
\hline Depression (BSI) & $62.8(20.74) ; 20$ & $63.72(18.06) ; 18$ & 52.13 (13.97); 16 & $61.53(17.88) ; 15$ & $52.92(12.58) ; 12$ & $57.2(11.38) ; 10$ \\
\hline Anxiety (BSI) & $63.00(25.84) ; 20$ & $57.33(13.21) ; 18$ & 51.44 (17.19); 16 & $54.47(11.34) ; 15$ & $54.00(14.83) ; 12$ & $54.40(7.81) ; 10$ \\
\hline Global severity of symptoms (BSI) & $68.20(22.62) ; 20$ & $61.47(15.84) ; 18$ & $54.44(18.42) ; 16$ & $57.27(12.31) ; 15$ & $56.92(18.47) ; 12$ & $53.40(11.58) ; 10$ \\
\hline Global functioning (GAF) & $52.77(10.31) ; 26$ & 53.74 (10.49); 23 & $62.76(11.69) ; 17$ & $67.24(13.05) ; 17$ & $65.67(14.63) ; 12$ & $63.14(16.45) ; 14$ \\
\hline Social functioning (SOFAS) & $52.52(10.75) ; 27$ & $56.71(11.75) ; 24$ & $61.94(12.40) ; 17$ & $68.41(13.83) ; 17$ & 66.08 (15.29); 12 & $63.93(16.82) ; 14$ \\
\hline \multicolumn{7}{|l|}{ Quality of life (QLS) } \\
\hline Intrapsychic & 25.43 (9.49); 28 & $26.23(7.63) ; 26$ & $27.94(8.20) ; 16$ & 31.18 (6.17); 17 & 29.42 (9.05); 12 & $31.20(4.87) ; 15$ \\
\hline Interpersonal & 26.43 (11.79); 28 & $26.00(9.71) ; 26$ & $29.40(12.56) ; 15$ & $32.24(12.22) ; 17$ & 32.67 (13.88); 12 & $32.80(10.93) ; 15$ \\
\hline \multicolumn{7}{|l|}{$\begin{array}{l}\text { Substance misuse } \\
\text { (OTI Mean use per day use, SD) }\end{array}$} \\
\hline Alcohol (drinks) & $0.28(0.72) ; 27$ & 1.42 (3.48); 26 & 4.18 (8.89); 11 & $1.39(2.11) ; 13$ & $2.67(4.36) ; 8$ & 2.44 (3.14); 11 \\
\hline $\begin{array}{l}\text { Cannabis } \\
\text { (joints/cones) }\end{array}$ & $0.90(3.87) ; 28$ & $0.00(0.01) ; 27$ & 11.67 (26.90); 6 & $0.04(0.06) ; 5$ & $0.57(0.96) ; 4$ & $2.75(3.89) ; 2$ \\
\hline Tobacco (cigarettes) & $3.91(7.64) ; 28$ & $2.04(4.81) ; 27$ & $3.10(4.55) ; 13$ & $3.79(4.64) ; 11$ & $7.15(7.22) ; 8$ & $7.31(6.60) ; 8$ \\
\hline Poly drug & $0.82(0.98) ; 28$ & 0.89 (1.09); 27 & $0.31(1.40) ; 16$ & $1.18(1.13) ; 17$ & 1.42 (1.24); 12 & 1.33 (1.35); 15 \\
\hline
\end{tabular}

younger sample, and prevents further analysis of the characteristics of those who transitioned. While our sample had an average age of 16 years, most trials have recruited from 18 years and older, or had a mean age over 20 years (Bechdolf et al., 2012; Morrison et al., 2012; van der Gaag et al., 2013). The lack of a treatment effect for CBT may have been in part due to difficulty for younger adolescents to fully engage in a CBT intervention despite our strong focus on behavioural experiments to enhance relevance and learning. Interestingly, our findings are consistent with another trial that also used the EDIE based CBT manual (Addington et al., 2011), which had a 6\% transition rate and the majority of the sample were working or studying as reflected in the relatively higher mean GAF scores of 59 . The authors argue that the lack of treatment effect arose from an insufficient dose of CBT in that $25 \%$ had dropped out of the trial by six months and much of the CBT sessions focused on assessment and engagement rather than core CBT strategies.

Meta-analysis of psychological and other interventions for UHR for psychosis reported incomplete outcome data for all included trials and concluded that this reflected a high rate of attrition in studies of this population (Stafford et al., 2013), rather than a methodological flaw. In our trial around one third of young people completed 12 treatment sessions or more of either CBT or NDRL. While many adult intervention trials offer treatment over a six month period, interventions with young people show the average number of completed sessions to be around 12 sessions, even when offered therapy over six months (Jackson et al., 2009).

In terms of functional outcomes, we did not apply the same strict inclusion criteria of some trials, such as a SOFAS rating of 50 or below (van der Gaag et al., 2013). Hence, the baseline SOFAS average of 53 suggests our sample was higher functioning than other trials (Morrison et al., 2012; van der Gaag et al., 2013) and thus there may have been a ceiling effect. Further comparisons of functional levels of other samples is hindered by the lack of reporting by trials of a social functioning measure, engagement in work or study, and housing arrangements (Amminger et al., 2010; Morrison et al., 2012). However, an inspection of CAARMS scores showed our sample had lower levels of psychotic like symptoms compared to other trials (Bechdolf et al., 2012; Ising et al., 2015). Thus our sample was younger, with better overall functioning and milder psychotic like symptoms compared to trials reported in the published meta-analyses.

The improvement for both groups in the frequency and intensity of psychotic experiences suggests a natural recovery process and has been seen in other trials (McGorry et al., 2013; Morrison et al., 2012). Alternatively, it may be due to the effectiveness of our active control condition, or the lack of validity of the UHR concept. Morrison et al. (Morrison et al., 2012) found cognitive therapy reduced intensity and frequency of psychotic symptoms but not distress or transition.

Table 3

Estimates of adjusted treatment effect (common to all follow-up times), standard errors, $95 \%$ confidence intervals, p-values and number included in the analysis.

\begin{tabular}{|c|c|c|c|c|}
\hline Measure & Treatment effect (Boot SE) & $95 \% \mathrm{CI}$ & p-Value & $\mathrm{N}$ \\
\hline CAARMS intensity & $0.94(0.88)$ & -0.78 to 2.66 & 0.283 & 52 \\
\hline CAARMS frequency & $2.06(1.09)$ & -0.07 to 4.20 & 0.058 & 52 \\
\hline CAARMS distress & $36.71(16.84)$ & 3.71 to 69.71 & 0.029 & 45 \\
\hline Depression (BSI) & $-1.14(3.37)$ & -7.73 to 5.46 & 0.735 & 34 \\
\hline Anxiety (BSI) & $-1.81(3.12)$ & -7.92 to 4.30 & 0.561 & 34 \\
\hline Global severity of symptoms (BSI) & $-1.77(3.19)$ & -8.03 to 4.49 & 0.580 & 34 \\
\hline Global functioning (GAF) & $-3.03(2.81)$ & -8.54 to 2.48 & 0.281 & 46 \\
\hline Social functioning (SOFAS) & $-1.75(2.62)$ & -6.88 to 3.37 & 0.503 & 47 \\
\hline \multicolumn{5}{|l|}{ Quality of life total score } \\
\hline Intrapsychic & $-2.13(1.34)$ & -4.76 to 0.51 & 0.113 & 51 \\
\hline Interpersonal & $0.09(2.23)$ & -4.28 to 4.46 & 0.968 & 52 \\
\hline \multicolumn{5}{|l|}{ Substance misuse (OTI) } \\
\hline Alcohol & $1.03(0.77)$ & -0.49 to 2.55 & 0.183 & 43 \\
\hline Cannabis & $2.47(2.44)$ & -2.32 to 7.26 & 0.312 & 26 \\
\hline Tobacco & $-1.25(1.21)$ & -3.64 to 1.13 & 0.302 & 38 \\
\hline Poly drug & $0.25(0.25)$ & -0.26 to 0.76 & 0.331 & 52 \\
\hline
\end{tabular}




\subsection{Methodological strengths and limitations}

The trial was a robust design with the use of an active control condition, assessors blinded to treatment allocation and fidelity checks on both conditions. The active control group allowed for the control of non-specific aspects associated with being involved in a therapeutic relationship. For example, both interventions provided equivalent contact with an empathic therapist. Having therapists provide both forms of the interventions was also a strength of the study, as this controlled for 'static' therapist effects, such as therapist age, gender, and level of experience. Common factors include client expectancy, providing a rationale for change, therapist factors and therapeutic alliance (Tarrier et al., 2004).

Consistent with other studies of UHR young people, there were difficulties recruiting to the trial with $25 \%$ fewer participants than planned and thus the trial was underpowered. The recruitment phase was funded for two years only and thus we were unable to continue to recruit beyond this time. While having therapists provide both types of therapy was a design strength, previous research has indicated that treatment outcomes may be influenced by the therapists' belief in the therapeutic model, irrespective of therapeutic alliance (Messer and Wampold, 2002). Unfortunately, strength of therapist belief in therapy model delivered was not measured in this trial.

\section{Conclusions}

The significant treatment effect for our active control condition, NDRL, supports the recommendations for a stepped care approach in the treatment of psychosis (McGorry et al., 2009). This is particularly important for early intervention with UHR young people who may benefit from a focus on non-psychotic symptoms in order to improve functioning and social inclusion. We suggest that transition to psychosis is not a useful primary outcome in UHR trials given the low transition rates evident in these samples. For UHR young people we propose a stepped care plan progressing from: (i) engagement and support; (ii) stress reduction and affect regulation; to (iii) normalization and a focus on distress associated with psychotic symptoms. A younger age group such as we had in our trial may benefit from lower level or less complex interventions (compared to CBT) such as active engagement and support in the first stage of intervention. Our results suggest the younger age group may be less receptive to CBT and thus alternative approaches might be considered.

\section{Funding}

The DEPTh trial was funded by the National Health and Medical Research Council, NHMRC (Grant number: 401230) and registered with the Australian New Zealand Clinical Trials Register (ACTRN12606000101583). Ulrich Schall and Vaughan Carr were supported by the Schizophrenia Research Institute utilizing infrastructure funding from the New South Wales Ministry of Health and New South Wales Ministry of Trade and Investment (Australia).

\section{Contributors/Authors}

Helen J Stain: Lead author, chief investigator and therapist on the trial; coordinated co-author contributions and advised statistician; clinical advisor; wrote significant proportion of paper.

Sean A Halpin: Co-Investigator on trial, coordinated clinical input; contributed to each section of the paper.

Amanda L Baker: Chief Investigator on trial; advised on drug and alcohol abuse data; contributed to each section of the paper.

Mike Startup: Lead Investigator on trial; responsible for original conception of the trial; unfortunately died from illness recently.
Vaughan J Carr: Chief Investigator on trial; assisted with clinical and in particular medical interpretation of data; contributed to each section of the paper.

Ulrich Schall: Chief Investigator on trial; assisted with clinical and in particular medical interpretation of data; contributed to each section of the paper and in particular the discussion.

Kylie Crittenden: Therapist and Project/coordinator for Rural site; assisted with the interpretation of rural data; contributed to each section of the paper.

Vanessa Clark: Therapist for trial in urban site; contributed to the collection of data, running of trial; contributed to each section of the paper and in particular the discussion.

Terry J Lewin: Co-Investigator on trial; led the statistical design and baseline analysis of the trial; contributed to each section of the paper and in particular the results and discussion.

Richard Emsley: Statistician who led the final outcome analysis for the trial due to substantial experience with RCTs, particularly for psychological interventions.

\section{Conflict of interest}

The authors have no conflicts of interest.

\section{Acknowledgements}

We thank the study participants and the staff who facilitated recruitment. We are grateful to Hunter New England and Greater Western Area Health Services, research assistants and therapists, including Jodie Fleming, Kylie Crittenden, Kristy Payne, Vicki Lynar and Madeleine de Ville. We would also like to acknowledge the passing of Professor Startup during the preparation of this paper.

\section{References}

Adamson, S., Kay-Lambkin, F., Baker, A., Lewin, T., Thornton, L., Kelly, B., Sellman, J.D., 2010. An improved brief measure of cannabis misuse: the cannabis use disorders identification test-revised (CUDIT-R). Drug Alcohol Depend. 110 (1-2), 137-143.

Addington, J., Epstein, I., Liu, L., French, P., Boydell, K.M., Zipursky, R.B., 2011. A randomized controlled trial of cognitive behavioral therapy for individuals at clinical high risk of psychosis. Schizophr. Res. 125 (1), 54-61.

Amminger, G.P., Schäfer, M.R., Papageorgiou, K., Klier, C.M., Cotton, S.M., Harrigan, S.M., Mackinnon, A., McGorry, P.D., Berger, G.E., 2010. Long-chain $\omega$-3 fatty acids for indicated prevention of psychotic disorders: a randomized, placebo-controlled trial. Arch. Gen. Psychiatry 67 (2), 146-154

Association, A.P, 1994. Diagnostic and Statistical Manual of Mental Disorders American Psychiatric Association. Washington, DC, pp. 471-475.

Babor, T.F., Higgins-Biddle, J.C., Saunders, J.B., Monteiro, M.G., 2001. AUDIT. The Alcohol Use Disorders Identification Test. Guidelines for Use in Primary Care., in: Department of Mental Health and Substance Dependence, W.H.O.W. (Ed.).

Bechdolf, A., Wagner, M., Ruhrmann, S., Harrigan, S., Putzfeld, V., Pukrop, R., BrockhausDumke, A., Berning, J., Janssen, B., Decker, P., 2012. Preventing progression to firstepisode psychosis in early initial prodromal states. Br. J. Psychiatry 200 (1), 22-29.

Bell, K., Startup, M., French, P., Morrison, A., Bucci, S., Fowler, D., 2008. Therapist Treatment Adherence in CBT for People at Ultra-High Risk for Psychosis: Development of a New Rating Scale, Early Intervention in Psychiatry. WILEY-BLACKWELL PUBLISHING, INC, p. A16.

Carr, V., Halpin, S., Lau, N., O'Brien, S., Beckmann, J., Lewin, T., 2000. A risk factor screening and assessment protocol for schizophrenia and related psychosis. Aust. N. Z. J. Psychiatry 34 (sup2), S170-S180.

Cartwright-Hatton, S., Wells, A., 1997. Beliefs about worry and intrusions: the meta-cognitions questionnaire and its correlates. J. Anxiety Dis. 11 (3), 279-296.

Chapman, J.P., 1966. The early symptoms of schizophrenia. Br. J. Psychiatry 112, 225-251.

Conrad, A.M., Lewin, T.J., Sly, K.A., Schall, U., Halpin, S.A., Hunter, M., Carr, V.J., 2014. Tenyear audit of clients presenting to a specialised service for young people experiencing or at increased risk for psychosis. BMC Psychiatry 14 (1), 318.

Darke, S., Hall, W., Wodak, A., Heather, N., Ward, J., 1992. Development and validation of a multi-dimensional instrument for assessing outcome of treatment among opiate users: the opiate treatment index. Br. J. Addict. 85 (5), 733-742.

Derogatis, L., 1995. Brief Symptom Inventory, in: Research, C.P. (Ed.), Baltimore, MD.

First, M., Spitzer, R., Gibbon, M., Williams, J., 1996. Structured Clinical Interview for DSMIV Axis I Disorders - Clinician Version (SCID-CV), in: Press, A.P. (Ed.), Washington, DC.

Fisher, J.R., de Mello, M.C., 2011. Using the World Health Organization's 4S framework to strengthen national strategies, policies and services to address mental health problems in adolescents in resource-constrained settings. Int. J. Ment. Heal. Syst. 5 (23).

French, P., Morrison, A.P., 2004. Early Detection and Cognitive Therapy for People at High Risk of Developing Psychosis: A Treatment Approach. John Wiley \& Sons.

Fusar-Poli, P., Bonoldi, I., Yung, A.R., Borgwardt, S. Kempton, M.J., Valmaggia, L., Barale, F., Caverzasi, E., McGuire, P., 2012. Predicting psychosis: meta-analysis of transition outcomes in individuals at high clinical risk. Arch. Gen. Psychiatry 69 (3), 220-229.

Goldman, H.H., Skodol, A.E., Lave, T.R., 1992. Revising axis V for DSM-IV: a review of measures of social functioning. Am. J. Psychiatry 149 (9), 1148-1156. 
Gossop, M., Darke, S., Griffiths, P., Hando, J., Powis, B., Hall, W., Strang, J., 1995. The severity of dependence scale (SDS): psychometric properties of the SDS in English and Australian samples of heroin, cocaine and amphetamine users. Addiction 90 (5), 607-614.

Heinrichs, D.W., Hanlon, T.E., Carpenter, W.T., 1984. The quality of life scale: an instrument for rating the schizophrenic deficit syndrome. Schizophr. Bull. 10 (3), 388.

Hutton, P., Taylor, P.J., 2014. Cognitive behavioural therapy for psychosis prevention: a systematic review and meta-analysis. Psychol. Med. 44 (03), 449-468.

Ising, H., Smit, F., Veling, W., Rietdijk, J., Dragt, S., Klaassen, R., Savelsberg, N., Boonstra, N., Nieman, D., Linszen, D., 2015. Cost-effectiveness of preventing first-episode psychosis in ultra-high-risk subjects: multi-centre randomized controlled trial. Psychol. Med. 45 (07), 1435-1446.

Jackson, C., Trower, P., Reid, I., Smith, J., Hall, M., Townend, M., Barton, K., Jones, J., Ross, K., Russell, R., 2009. Improving psychological adjustment following a first episode of psychosis: a randomised controlled trial of cognitive therapy to reduce post psychotic trauma symptoms. Behav. Res. Ther. 47 (6), 454-462.

Kaufman, J., Birmaher, B., Brent, D., Rao, U., Flynn, C., Moreci, P., Williamson, D., Ryan, N., 1997. Schedule for affective disorders and schizophrenia for school-age childrenpresent and lifetime version (K-SADS-PL): initial reliability and validity data. J. Am. Acad. Child Adolesc. Psychiatry 36 (7), 980-988.

Kessler, R.C., Berglund, P., Demler, O., Jin, R., Merikangas, K.R., Walters, E.E., 2005. Lifetime prevalence and age-of-onset distributions of DSM-IV disorders in the National Comorbidity Survey Replication. Arch. Gen. Psychiatry 62 (6), 593-602.

McGorry, P.D., Nelson, B., Amminger, G.P., Bechdolf, A., Francey, S.M., Berger, G., RiecherRossler, A., Klosterkotter, J., Ruhrmann, S., Schultze-Lutter, F., 2009. Intervention in individuals at ultra-high risk for psychosis: a review and future directions. J. Clin. Psychiatry 70 (9), 1206.

McGorry, P.D., Nelson, B., Phillips, L.J., Yuen, H.P., Francey, S.M., Thampi, A., Berger, G.E., Amminger, G.P., Simmons, M.B., Kelly, D., 2013. Randomized controlled trial of interventions for young people at ultra-high risk of psychosis: twelve-month outcome. J. Clin. Psychiatry 74 (4), 349-356.

McGorry, P.D., Yung, A.R., Phillips, L.J., Yuen, H.P., Francey, S., Cosgrave, E.M., Germano, D., Bravin, J., McDonald, T., Blair, A., 2002. Randomized controlled trial of interventions designed to reduce the risk of progression to first-episode psychosis in a clinical sample with subthreshold symptoms. Arch. Gen. Psychiatry 59 (10), 921-928.

Messer, S.B., Wampold, B.E., 2002. Let's face facts: common factors are more potent than specific therapy ingredients. Clin. Psychol. Sci. Pract. 9 (1), 21-25.

Morgan, V.A., Waterreus, A., Jablensky, A., Mackinnon, A., McGrath, J.J., Carr, V., Bush, R., Castle, D., Cohen, M., Harvey, C., 2012. People living with psychotic illness in 2010: the second Australian national survey of psychosis. Aust. N. Z. J. Psychiatry 46 (8), $735-752$.
Morrison, A.P., French, P., Stewart, S.L., Birchwood, M., Fowler, D., Gumley, A.I., Jones, P.B. Bentall, R.P., Lewis, S.W., Murray, G.K., 2012. Early detection and intervention evaluation for people at risk of psychosis: multisite randomised controlled trial. BMJ 344.

Morrison, A.P., French, P., Walford, L., Lewis, S.W., Kilcommons, A., Green, J., Parker, S. Bentall, R.P., 2004. Cognitive therapy for the prevention of psychosis in people at ultra-high risk randomised controlled trial. Br. J. Psychiatry 185 (4), 291-297.

Nelson, B., Yuen, H.P., Wood, S.J., Lin, A., Spiliotacopoulos, D., Bruxner, A., Broussard, C. Simmons, M., Foley, D.L., Brewer, W.J., 2013. Long-term follow-up of a group at ultra high risk ("prodromal") for psychosis: the PACE 400 study. JAMA psychiatry 70 (8), 793-802.

Patel, V., Flisher, A.J., Hetrick, S., McGorry, P., 2007. Mental health of young people: a global public-health challenge. Lancet 369 (9569), 1302-1313.

Rosenberg, M., 1965. Society and the Adolescent Self-Image, in: Press, P.U. (Ed.), Princeton, NJ.

Sellman, J., MacEwan, I., Deering, D., Adamson, S., 2007. A comparison of motivational interviewing with non-directive counseling. Motivational Dialogue: Preparing Addiction Professionals for Motivational Interviewing Practice, pp. 137-150.

Sellman, J.D., P.F., S., G.M., D., 2001. Brief Treatment Programme for Alcohol Dependence: Person-Centred Therapy Therapists Manual. Medicine, Christchurch School of

Stafford, M.R., Jackson, H., Mayo-Wilson, E., Morrison, A.P., Kendall, T., 2013. Early interventions to prevent psychosis: systematic review and meta-analysis. BMJ 346, f185.

Tarrier, N., Lewis, S, Haddock, G., Bentall, R., Drake, R. Kinderman, P., Kingdon, D., Siddle, R., Everitt, J., Leadley, K., 2004. Cognitive-behavioural therapy in first-episode and early schizophrenia. Br. J. Psychiatry 184 (3), 231-239.

UNICEF, 2012. Progress for Children: A Report Card on Adolescents-Number 10, April. , in: Communication, U.D.o. (Ed.), New York.

van der Gaag, M., Smit, F., Bechdolf, A., French, P., Linszen, D.H., Yung, A.R., McGorry, P., Cuijpers, P., 2013. Preventing a first episode of psychosis: meta-analysis of randomized controlled prevention trials of 12 month and longer-term follow-ups. Schizophr. Res. 149 (1), 56-62.

WHO, 2008. The Global Burden of Disease: 2004 Update.

Yung, A.R., McGorry, P.D., 1996. The prodromal phase of first-episode psychosis: past and current conceptualizations. Schizophr. Bull. 22 (2), 353-370.

Yung, A.R., Pan Yuen, H., Mcgorry, P.D., Phillips, L.J., Kelly, D., Dell'olio, M., Francey, S.M. Cosgrave, E.M., Killackey, E., 2005. Mapping the onset of psychosis: the comprehensive assessment of at-risk mental states. Aust. N. Z. J. Psychiatry 39 (11-12), 964-971. 